Fall 10-1-2015

\title{
Endonasal Vascularized Flaps For Cranial Base Reconstruction
}

\author{
Hyunwoo Do, MD \\ Thomas Jefferson University \\ Alexander Farag, MD \\ The Ohio State University, Columbus $\mathrm{OH}$ \\ Varun Kshettry, MD \\ Thomas Jefferson University \\ Gurston G. Nyquist, MD \\ Thomas Jefferson University \\ Marc R. Rosen, MD \\ Thomas Jefferson University
}

See next page for additional authors

Follow this and additional works at: https://jdc.jefferson.edu/jhnj

\section{Let us know how access to this document benefits you}

\section{Recommended Citation}

Do, MD, Hyunwoo; Farag, MD, Alexander; Kshettry, MD, Varun; Nyquist, MD, Gurston G.; Rosen, MD, Marc R.; Evans, MD, James J.; and Farrell, MD, Christopher J (2015) "Endonasal Vascularized Flaps For Cranial Base Reconstruction," JHN Journal: Vol. 10 : Iss. 2 , Article 8.

DOI: https://doi.org/10.29046/JHNJ.010.2.004

Available at: https://jdc.jefferson.edu/jhnj/vol10/iss2/8

This Article is brought to you for free and open access by the Jefferson Digital Commons. The Jefferson Digital Commons is a service of Thomas Jefferson University's Center for Teaching and Learning (CTL). The Commons is a showcase for Jefferson books and journals, peer-reviewed scholarly publications, unique historical collections from the University archives, and teaching tools. The Jefferson Digital Commons allows researchers and interested readers anywhere in the world to learn about and keep up to date with Jefferson scholarship. This article has been accepted for inclusion in JHN Journal by an authorized administrator of the Jefferson Digital Commons. For more information, please contact: JeffersonDigitalCommons@jefferson.edu. 


\section{Endonasal Vascularized Flaps For Cranial Base Reconstruction}

\section{Authors}

Hyunwoo Do, MD; Alexander Farag, MD; Varun Kshettry, MD; Gurston G. Nyquist, MD; Marc R. Rosen, MD; James J. Evans, MD; and Christopher J Farrell, MD 


\section{Endonasal Vascularized Flaps For Cranial Base Reconstruction}

\author{
Hyunwoo Do, MD1; Alexander Farag MD²; Varun Kshettry, MD; \\ Gurston G. Nyquist, MD³; Marc R. Rosen, MD 1,3; James J. Evans, MD 1,3; \\ Christopher J. Farrell, $\mathrm{MD}^{1}$ \\ 1Department of Neurological Surgery, Thomas Jefferson University, Philadelphia, PA
${ }^{2}$ Department of Otolaryngology, The Ohio State University, Columbus, OH
${ }^{3}$ Department of Otolaryngology, Thomas Jefferson University, Philadelphia, PA
}

\section{INTRODUCTION}

Since the introduction of extended endoscopic cranial base surgery, postoperative cerebrospinal fluid (CSF) leak has been a formidable and troublesome issue resulting in complications such meningitis, pneumocephalus, and the need for additional surgical interventions. Establishment of a watertight cranial base reconstruction is the most critical step in preventing postoperative CSF leakage. Historically, various free grafts, both synthetic and autologous, were utilized as repair materials for reconstruction of the cranial base defect often in combination with temporary CSF diversion. Free grafts are often sufficient for repair of small low flow, low pressure dural defects. High postoperative CSF leak rates reported in the initial endoscopic skull base literature are evidence that free grafts do not provide a reliably competent repair for large defects or direct high-flow CSF leaks. The introduction of the Hadad-Bassagasteguy vascularized nasoseptal flap has significantly reduced the reported CSF leak rate with a recent meta-analysis reporting that use of the vascularized flap is associated with a $7 \%$ rate of postoperative CSF leakage compared to $16 \%$ with free grafts alone for large dural defects. ${ }^{6}$ Since the initial description of the vascularized pedicled nasoseptal flap in 2006, many surgeons have developed a variety of alternative vascularized flaps for endonasal cranial base reconstruction. In this article, we summarize and compare several of the most clinically useful vascularized flaps including their harvest technique, indications and limitations, and potential complications.
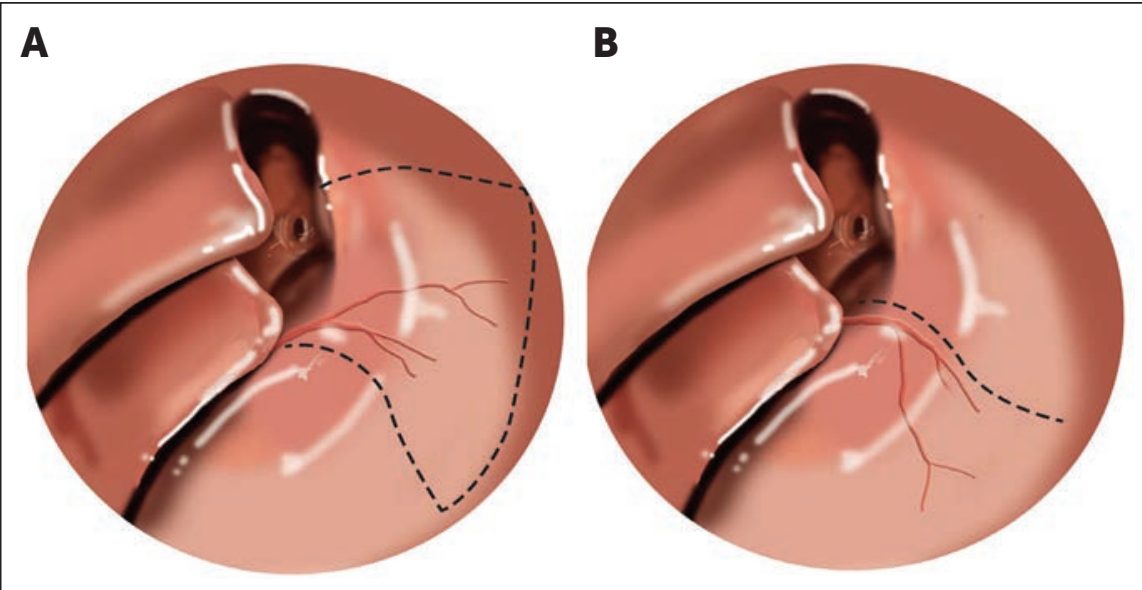

Figure 1

(A) Incisions (dotted lines) for standard Nasoseptal Flap and (B) Rescue Flap.

\section{PEDICLED NASOSEPTAL FLAP}

The pedicled nasoseptal flap (NSF) as described by Hadad and colleagues is a mucoperiosteal and mucoperichondrial flap of the nasal septum based on the nasoseptal artery, a branch of the sphenophalatine artery. ${ }^{5}$ The nasoseptal flap is extremely versatile and allows for an extensive area of coverage with cadaveric studies demonstrating a mean NSF surface area of $17 \mathrm{~cm} .^{2,9}$ The harvested NSF varies between $5-8 \mathrm{~cm}$ in length and $5 \mathrm{~cm}$ in width, enabling reconstruction from the posterior wall of the frontal sinus to the clivus in the sagittal plane and from orbit to orbit. ${ }^{3-4}$ The flap's rich and long vascular pedicle with multiple branches and anastomoses provides consistent vascularity, allowing it to be harvested early in the course of surgery and stored in the nasopharynx as well as re-mobilized should future surgeries be necessary. The major drawback of the NSF is that it must be harvested during the initial stages of endonasal surgery before any disruption of the vascular supply has occurred. Additionally, harvest of the NSF creates a large anterior mucosal defect at the donor site, resulting in significant postoperative nasal crusting and need for multiple debridements. Although postoperative olfactory dysfunction is typically transient, higher rates of permanent olfactory loss have been reported in patients undergoing extended approaches with NSF elevation. ${ }^{12,14}$ Nasal septal perforation may also rarely occur. ${ }^{15}$

An understanding of the vascular supply to the nasal septum is critical for successful harvest of a robust NSF. The sphenopalatine artery is a terminal branch of the internal maxillary artery. It exits the pterygopalatine fossa and enters the nasal cavity through the sphenopalatine foramen before dividing into the posterior lateral nasal artery and nasoseptal artery. The NSF is developed by creating two parallel incisions in the 


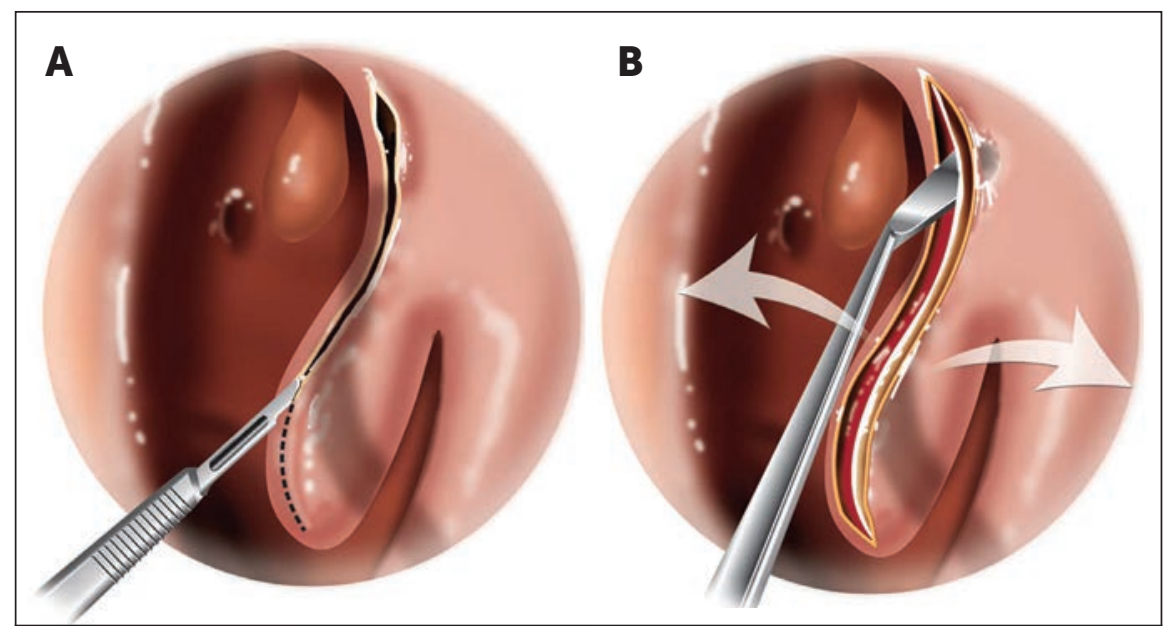

Figure 2

(A) Incision for Middle Turbinate Flap. (B) The flap is then spread like an "open book".
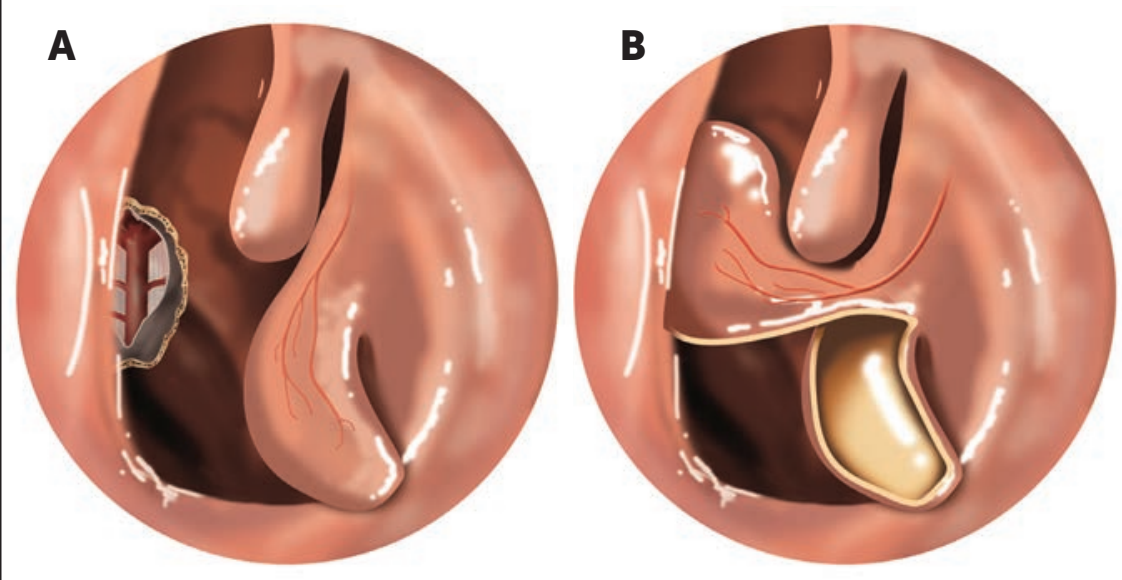

Figure 3

(A) Incision for harvest of the Inferior Turbinate Flap which is suitable for covering small clival defects (*). (B) After removal of the inferior turbinate, the flap is rotated to provide coverage.

sagittal plane along the septum with an anterior vertical connecting incision. Electrocautery or cold steel may be used for harvest with electrocautery having the advantage of minimizing bothersome oozing throughout the surgery but slightly diminishing the end-size of the flap. The superior incision begins at the superior aspect of the sphenoid os and is carried anteriorly and superiorly at the level of the superior turbinate. A 1 to $2 \mathrm{~cm}$ strip of the superior septum is preserved to minimize an olfactory deficit. The anterior extent, or size of the flap depends on the coverage area anticipated. Lack of preservation of the superior strip may result in anosmia. The inferior incision is made along the floor of the nasal cavity and may be extended laterally until under the inferior turbinate if wider coverage is necessary, although this increases the risk of superior alveolar nerve injury (Figure 1). One of the main limitations of the NSF is that it must be harvested early during the course of surgery before its blood supply is disrupted. Although the NSF can be harvested routinely and returned to its normal position should a vascularized flap not prove necessary, this routine practice is time consuming and carries all of the potential risks of NSF harvest including nasal crusting, septal perforation, prolonged healing, and anosmia. For certain endonasal procedures such as pituitary surgery, reconstruction with the NSF is rarely necessary. Elsewhere in this journal we describe the TJUH approaches to the skull base that preserve the vascular supply to the NSF including the "1.5" and submucosal "tunnel" approaches. Other groups have developed similar modifications designed to allow for delayed NSF harvest. Rivera-Serrano et al. and Griffiths et al. have described their "rescue flap" modifications which preserve the NSF blood supply while enabling a bilateral sphenoidotomy and limited posterior septectomy to be performed for access to the sella. ${ }^{4,11}$ In these modifications, the superior incision of the NSF is performed and the in underlying mucosa inferiorly is elevated with preservation of the vascular pedicle and the superior olfactory strip (SOS). Mucoperiosteal incisions are made starting just inferior to the sphenoid ostium and extending laterally for a few millimeters. The incision is carried anteriorly and horizontally for approximately $2 \mathrm{~cm}$ along the perpendicular plate of the ethmoid and posterior nasal septum, and ending at a point opposite to the anterior border of the middle turbinate. It is then extended further anteriorly and superiorly in a hockey-shaped fashion to facilitate flap mobilization (Figure 1).

\section{TURBINATE FLAPS}

Although the NSF serves as the workhorse of endonasal cranial base reconstruction, its utility is limited for repair of more anteriorly located defects in the region of the frontal sinus 
and harvest of a vascularized NSF may not always be possible in the setting of prior surgery or malignancy where the septal mucosa may be compromised. As such, a variety of turbinate flaps have been described which are based on the blood supply to the lateral nasal wall. These turbinate flaps may be performed unilaterally or bilaterally as necessary to provide coverage.

\section{A. Middle Turbinate Flap}

The vascularized middle turbinate flap was first proposed in a 2009 cadaveric study. Since that time, a variety of clinical applications have been reported. ${ }^{10,13}$ The posterior lateral nasal artery, a branch of sphenopalatine artery, serves as the vascular pedicle for the middle turbinate flap and the flap best suited for coverage of small- to moderate-sized dural defects in the sellar, planum sphenoidale and fovea ethomoidalis areas. Coverage of the olfactory groove and mid- to lower-clival regions is not possible with the middle turbinate flap. The reported a mean surface area for the flap of $5.6 \mathrm{~cm}^{2}$ with the length ranging from approximately $3-4 \mathrm{~cm}$ and width of $1-2 \mathrm{~cm} .^{3}$ Coverage of sellar defects requires that a flap $4 \mathrm{~cm}$ length should be secured and preoperative measurement of the middle turbinate length using imaging can be used to predict the available flap length.

The flap is harvested by creating a vertical incision along the anterior face of the middle turbinate. Subperiosteal elevation of the mucoperiosteum is carried out bilaterally along the medial and lateral slopes of the turbinate. Once the mucoperiosteum has been raised, the bony turbinate is removed and a cut is made through the middle turbinate's axilla. The incision is extended dorso-caudally along the sagittal plane until the mucosa is completely divided and unfolded in an open book fashion, taking great care to not disrupt the blood supply to the flap. It is critical that the incisions at the medial and lateral aspect of the turbinate remain below the level of the ethmoids and cribriform plate to avoid iatrogenic CSF leakage (Figure 2). Aberrant pneumatization of the turbinate may also lead to inadvertent leakage. Similar to the NSF, some postoperative crusting is to be expected. ${ }^{13}$

\section{B. Inferior Turbinate Flap}

In 2007, Fortes et al. reported a posterior pedicle inferior turbinate flap (PPITF). For this flap, the vascular pedicle is supplied from the inferior turbinate artery, a terminal branch of the posterior lateral nasal artery. ${ }^{2}$ The inferior turbinate artery enters the inferior turbinate posteriorly along its lateral surface. ${ }^{8}$ Inferior turbinate flap is indicated for smaller defects of the sella, posterior fossa and clivus. The reported size of the flap varies widely in the literature with the length of the flap ranging from $2-5 \mathrm{~cm}$ (Table 1). Unless the flap is extended along the lateral nasal wall, the flap is narrow in width ranging from $1.2-1.4 \mathrm{~cm}^{3}$ Because of its origin near the nasal cavity floor and limited arc of rotation, the inferior turbinate flap is not recommended for anterior skull base coverage. Crusting occurs over the exposed inferior turbinate bone and requires frequent debridement.

The flap is harvested by creating two parallel incisions along the superior and inferior aspects of the turbinate and connected with an anterior vertical incision along the head of the turbinate. Importantly, the vascular pedicle is located along the superior aspect of the inferior turbinate's lateral attachment. Additionally, it is important to preserve the lateral nasal artery as it descends vertically over the ascending process of the palatine bone and care must be taken not to injure nasolacrimal duct during the harvest (Figure 3).

\section{Superior Turbinate Flap}

Superior turbinate osteoplastic (STOP) flap is novel method developed by Thomas Jefferson University Hospital Cranial Base Team (see additional article in this edition for further details). This is a suitable alternative for anterior skull base coverage when the NSF is unavailable or compromised. The superior turbinate has multiple arterial feeders from the nasoseptal artery, posterior lateral nasal artery, and posterior ethmoidal artery. Its proximity to the anterior skull base and ample blood supply make the superior turbinate a convenient source for vascularized reconstruction. The STOP flap utilizes both the superior turbinate bone and mucosa with the composite nature providing additional support and rigidity.
The main limitation of the STOP flap is the limited size of the superior turbinate and its variability among individuals. Additionally, the limited arc of rotation of the STOP flap restricts its use to the anterior skull base.

To harvest the STOP flap, the lateral half of the superior turbinate mucosa is carefully removed with preservation of the underlying bone. The vascularized osteoplastic flap is then reflected. Care must be taken not to cover local mucosa by the STOP flap to avoid the risk of mucocele. Other complications are extremely rare and bilateral superior turbinate flaps may be utilized as necessary.

\section{TEMPOROPARIETAL FASCIA FLAP}

The temporoparietal flap (TPF), though used in a wide variety of reconstructive settings, was first described in 2007 for endoscopic endonasal reconstruction. ${ }^{16}$ Extensively described in the literature, it is the third layer located in the scalp below the skin and subcutaneous tissue. ${ }^{17}$ The flap is commonly supplied by anterior frontal branch of the superficial temporal artery (STA) with one or two veins accompanying the STA for drainage. ${ }^{3}$ TPF has a thickness of 2 to $3 \mathrm{~mm}$. ${ }^{18}$ The flap can be extended above the temporal line to include the gala, allowing the flap to as large as $14 \times 17 \mathrm{~cm} .{ }^{19}$ The temporoparietal flap requires an external incision making for a durable reconstruction when previous surgery or treatment precludes the use of intranasal pedicled flaps. This technically challenging flap has a low risk of alopecia and frontal nerve injury in experienced hands.

After the defect has been identified, a maxillary antrostomy and total ethmoidectomy are performed on the side which the flap will be raised. Next, the pterygopalatine fossa is completely opened as the entire posterior maxillary wall is removed. Particular attention is paid to the superior lateral aspect of the posterior maxillary wall. A hemicoronal incision is made in the scalp. The skin and subcutaneous tissue are dissected free exposing the lateral surface of the TPF. Meticulous and slow dissection must be undertaken here as the scalp has a rich vasculature and the pedicle vessels can easily be 
injured. In cases where a wide flap is needed, the frontal branch is identified as it courses though the frontalis muscle. Once adequate exposure is obtained, the flap is outlined and incised as the TPF is elevated off of the periosteum and temporalis muscle. The temporalis muscle has an origin on the lateral orbital rim, which must be released to communicate with the infratemporal fossa. Next a dilator is inserted to enlarge this communication producing a tunnel large enough to pull the flap though. The orientation of the pedicle is monitored to ensure it is not kinked or compressed. The pedicle can also be lengthened to extend the coverage intranasally.

\section{CONCLUSION}

Utilization of vascularized pedicled flaps in extended endoscopic endonasal skull base surgery has been shown to significantly reduce the CSF leak rate for large dural defect and high-flow CSF leaks. The NSF continues to be the workhorse flap for the reconstruction of skull base defects due to its versatility. However, a variety of other vascularized flaps can be used in combination with the NSF for more extensive coverage or as an alternative when the NSF is unavailable. Knowledge of each flap's indications, limitations, and pitfalls is critical to prepare for successful endoscopic skull base surgery.

\section{REFERENCES}

1. Amit M, Cohen J, Koren I, Gil Z: Cadaveric study for skull base reconstruction using anteriorly based inferior turbinate flap. The Laryngoscope 123:2940-2944, 2013

2. Fortes FSG, Carrau RL, Snyderman $\mathrm{CH}$, Prevedello D, Vescan A, Mintz A, et al.: The posterior pedicle inferior turbinate flap: a new vascularized flap for skull base reconstruction. The Laryngoscope 117:1329-1332, 2007

3. Gras-Cabrerizo JR, Gras-Albert JR, MonjasCanovas I, García-Garrigós E, Montserrat-Gili JR, Sánchez del Campo F, et al.: [Pedicle flaps based on the sphenopalatine artery: anatomical and surgical study]. Acta Otorrinolaringol Esp 65:242-248, 2014

4. Griffiths CF, Cutler AR, Duong HT, Bardo G, Karimi K, Barkhoudarian G, et al.: Avoidance of postoperative epistaxis and anosmia in endonasal endoscopic skull base surgery a technical note. Acta Neurochir (Wien) 156:1393-1401, 2014

5. Hadad G, Bassagasteguy L, Carrau RL, Mataza JC, Kassam A, Snyderman CH, et al.: A novel reconstructive technique after endoscopic expanded endonasal approaches: vascular pedicle nasoseptal flap. The Laryngoscope 116:1882-1886, 2006

6. Harvey RJ, Parmar P, Sacks R, Zanation AM: Endoscopic skull base reconstruction of large dural defects: a systematic review of published evidence. The Laryngoscope 122:452-459, 2012

7. Harvey RJ, Sheahan PO, Schlosser RJ: Inferior turbinate pedicle flap for endoscopic skull base defect repair. Am J Rhinol Allergy 23:522-526, 2009

8. Lee HY, Kim H-U, Kim S-S, Son EJ, Kim JW, Cho $\mathrm{NH}$, et al.: Surgical anatomy of the sphenopalatine artery in lateral nasal wall. The Laryngoscope 112:1813-1818, 2002

9. Pinheiro-Neto CD, Ramos HF, Peris-Celda M, Fernandez-Miranda JC, Gardner PA, Snyderman $\mathrm{CH}$, et al.: Study of the nasoseptal flap for endoscopic anterior cranial base reconstruction. The Laryngoscope 121:25142520, 2011
10. Prevedello DM, Barges-Coll J, FernandezMiranda JC, Morera V, Jacobson D, Madhok $\mathrm{R}$, et al.: Middle turbinate flap for skull base reconstruction: Cadaveric feasibility study. The Laryngoscope 119:2094-2098, 2009

11. Rivera-Serrano CM, Snyderman $\mathrm{CH}$, Gardner P, Prevedello D, Wheless S, Kassam AB, et al.: Nasoseptal "rescue" flap: a novel modification of the nasoseptal flap technique for pituitary surgery. The Laryngoscope 121:990-993, 2011

12. Rotenberg BW, Saunders S, Duggal N: Olfactory outcomes after endoscopic transsphenoidal pituitary surgery. The Laryngoscope 121:1611-1613, 2011

13. Simal Julián JA, Miranda Lloret $P$, Cárdenas Ruiz-Valdepeñas E, Barges-Coll J, Beltrán Giner A, Botella Asunción C: Middle turbinate vascularized flap for skull base reconstruction after an expanded endonasal approach. 2011, pp 1827-1832

14. Tam S, Duggal N, Rotenberg BW: Olfactory outcomes following endoscopic pituitary surgery with or without septal flap reconstruction: a randomized controlled trial. Int Forum Allergy Rhinol 3:62-65, 2013

15. Thorp BD, Sreenath SB, Ebert CS, Zanation AM: Endoscopic skull base reconstruction: a review and clinical case series of 152 vascularized flaps used for surgical skull base defects in the setting of intraoperative cerebrospinal fluid leak. Neurosurg Focus 37:E4 2014

16. Fortes FS, Carrau RL, Snyderman MD et al. Transpterygoid Transposition of a Temporoparietal Fascia Flap: A New Method for Skull Base Reconstruction after Endoscopic Expanded Endonasal Approaches. Laryngoscope. 2007;117(6):970-6.

17. Olson KL, Manolidis S. The pedicled super ficial fascial flap: a new method for reconstruction in otologic surgery. Otolaryngol Head Neck Surg 2002;126:538-547.

18. Moore KL, Dalley AF. Clinically oriented anatomy, ed 5. Baltimore: Lippincott Williams and Wilkins, 2006:788-798.

19. David SK, Cheney SL. An anatomic study of the temporoparietal fascia flap. Arch Otolaryngol Head Neck Surg. 1995;121:11531156 